\title{
Mechanical Properties of Post-fire Inorganic Polymer Concrete Columns under Eccentric Compression
}

\author{
Huiguo Chen, Yixin Lei*, Yue Zhao \\ Department of Military Installations, Army Logistics University of PLA, Chongqing 401331, China
}

Corresponding Author Email: 1yx19940907@126.com

https://doi.org/10.18280/rcma.290304

Received: 18 March 2019

Accepted: 29 May 2019

\section{Keywords:}

inorganic polymer concrete (IPC), high temperature, eccentric compression, mechanical properties

\begin{abstract}
This paper aims to disclose the variation law in the performance of inorganic polymer concrete (IPC) columns under varied temperatures. Therefore, the IPC columns were tested under eccentric compression at several high-temperature conditions, and multiple mechanical indices of each column were measured, including the compressive strength, axial deformation and lateral displacement. On this basis, the author analyzed the impacts of the hightemperature conditions on the mechanical properties of the IPC columns. The analysis shows that the compressive strength of the IPC columns was enhanced with the increase of fire temperature, and started to decline after the temperature surpassed $400{ }^{\circ} \mathrm{C}$; the loss ratio, i.e. the loss of compressive strength, of each IPC column under eccentric load, was smaller than that of the corresponding ordinary concrete column, under any high-temperature condition. The research results confirm the excellent fire-resistance of the IPC, shedding new light on fire prevention and post-fire evaluation.
\end{abstract}

\section{INTRODUCTION}

The column structure is widely used in various engineering projects. It has a direct bearing on the stability of buildings. However, the strength and rigidity of the column structure are greatly weakened by fire, posing a serious risk for the building to collapse. Thus, it is very meaningful to explore the post-fire mechanical properties of the column structure. Knowing these properties, the designers and relief workers can mitigate or eliminate the loss of mechanical strength and reduce local damages of the column structure at high temperature, lower the fire damage to the building structure, and facilitate postdisaster assessment and reinforcement [1-3].

Inorganic polymer concrete (IPC) [4-6] is a desirable material for the column structure. This novel inorganic cement-based composite enjoys many excellent properties: fast hardening, high early strength, environmental friendliness, energy efficiency, corrosion resistance and strong durability. Compared with ordinary concrete, the IPC features high tensile strength, good structural stability and strong crack resistance. With these advantages, the IPC enjoys good prospects for development $[7,8]$.

So far, many scholars have explored deeply into the performance of the IPC at normal or high temperature. For instance, You et al. [9] compared the post-pouring temperature field and stress field between the IPC and ordinary concrete through repeated tests, revealing that the IPC outperformed the ordinary concrete in crack resistance and brittleness. Kim et al. [10] structurally modified the carbon fiber reinforced polymer (CFRP) composite under thermal stress, observed the residual features of the organic and inorganic resins, and concluded that the organic resin properties depend heavily on the curing time and is affected by temperature. Chen et al. [11] conducted a static load test on five recycled aggregate reinforced concrete columns, compared these columns with a control sample under ambient temperature, and obtained the ultimate compressive strength, stress distribution and load deformation curve of these columns from their damage process and failure mode.

From the above, the physical properties of the IPC have been studied extensively $[12,13]$, but those of the IPC members have not. To make up for this gap, this paper carries out both experimental and theoretical analyses on the variation law in the compressive strength of IPC columns under eccentric load at different high-temperature conditions. The research results provide a reference for analyzing and evaluating the mechanical properties of post-fire IPC columns.

The remainder of this paper is organized as follows: Section 2 introduces the test plan, the test procedure and the sample design; Section 3 investigates the compressive properties of IPC columns with small and large eccentricities from four aspects, and highlights the differences between the IPC columns and ordinary concrete columns; Section 4 puts forward the conclusions based on the test and analysis results.

\section{METHODOLOGY}

\subsection{Sample design}

Table 1. The mix ratio of the IPC $\left(\mathrm{kg} / \mathrm{m}^{3}\right)$

\begin{tabular}{ccccc}
\hline $\begin{array}{c}\text { Slag } \\
\text { powder }\end{array}$ & $\begin{array}{c}\text { Fly } \\
\text { ash }\end{array}$ & $\begin{array}{c}\text { Alkali } \\
\text { activator }\end{array}$ & $\begin{array}{c}\text { River } \\
\text { sands }\end{array}$ & Gravels \\
\hline 360 & 90 & 186 & 644 & 1,196 \\
\hline
\end{tabular}

According to previous tests and computation, slag powder (activity level: S95) and fly ash (class: F; quality grade: II) were selected as the binding materials; continuously graded gravels (size: 5 25mm) were taken as coarse aggregates; ordinary river sands were adopted as the fine aggregates; 
sodium silicate solution (water content: $55 \%$ ), which was prepared from water glass, sodium hydroxide and tap water, was chosen as the alkali activator. The mix ratio of the IPC is explained in Table 1 below.
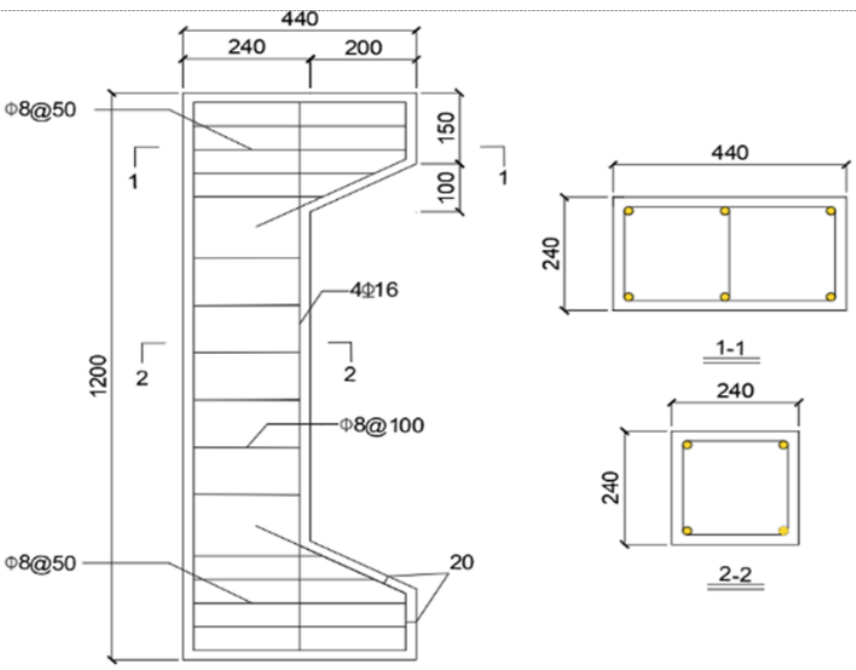

Figure 1. Size and reinforcement of the column
Each IPC column was designed with two corbels. The longitudinal bars are HRB400 steel bars, and the stirrups are HRB335 steel bars. The stirrups are denser at the corbels than the other positions. The sectional size of the column is $240 \mathrm{~mm} \times 240 \mathrm{~mm}$, the corbel length is $200 \mathrm{~mm}$, the net height of the column is $1,200 \mathrm{~mm}$, and the protective layer is $20 \mathrm{~mm}$ thick. The size and reinforcement of the column is shown in Figure 1.

The impacts of additional eccentricity were not considered because the columns in our test are relatively short. A total of eight test samples of IPC columns were prepared, including 4 with large eccentricity $(120 \mathrm{~mm})$ and 4 with small eccentricity $(50 \mathrm{~mm})$. On each column, 7 resistance strain gauges were arranged at the middle to measure the strain of concrete; 4 reinforcement strain gauges were placed at the middle of the longitudinal bars to capture the strain of reinforcement. The prepared columns were placed into the mold at once.

Meanwhile, three $100 \mathrm{~mm} \times 100 \mathrm{~mm} \times 100 \mathrm{~mm}$ control samples were also prepared and cured at the same condition as the test samples. After molding, all the samples were subjected to standard curing in a cool room for $24 \mathrm{~h}$. Then, the samples were demolded and numbered, followed by a $28 \mathrm{~d}$-long curing period. Finally, the samples were air-dried in an open place. The sample preparation procedure is illustrated in Figure 2.

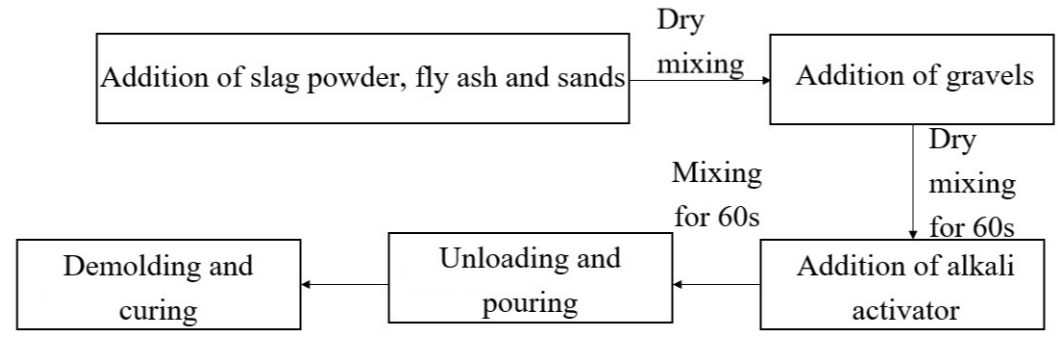

Figure 2. The procedure of sample preparation

\subsection{Design of high-temperature conditions}

During our tests, the test samples were loaded under high temperature in a gas furnace for fire resistance test. According to Pan's research $[14,15]$, the strength of the IPC decreases by over $65 \%$ under the high temperature of $800{ }^{\circ} \mathrm{C}$. Thus, it is not meaningful to explore the compressive strength of the IPC at a temperature higher than that level. Therefore, three levels of temperatures were studied in our tests, namely, normal temperature, $400{ }^{\circ} \mathrm{C}$ and $600{ }^{\circ} \mathrm{C}$. The samples were loaded for $1 \mathrm{~h}$ at each temperature. To disclose how fire time affects IPC properties, the samples were also loaded for $2 \mathrm{~h}$ at $600{ }^{\circ} \mathrm{C}$. The different test conditions and their numbers are listed in Table 2 .

Table 2. Sample geometry and test conditions

\begin{tabular}{ccccc}
\hline Conditions & Fire temperature & Fire time & Columns with large eccentricity & Columns with small eccentricity \\
\cline { 3 - 5 } & & & Serial number & Serial number \\
\hline I & Normal temperature & - & DP1 & XP5 \\
II & $400^{\circ} \mathrm{C}$ & Constant temperature for $1 \mathrm{~h}$ & DP2 & XP6 \\
III & $600^{\circ} \mathrm{C}$ & Constant temperature for $1 \mathrm{~h}$ & DP3 & XP7 \\
IV & $600^{\circ} \mathrm{C}$ & Constant temperature for $2 \mathrm{~h}$ & DP4 & XP8 \\
\hline
\end{tabular}

The ISO 834-1 standard temperature rise curve was adopted to control the temperature. In each test condition, the actual temperature was recorded by thermocouples embedded in the sample. Once the temperature reached the specified level, the gas furnace was shutdown to maintain the temperature at that level. The sample was taken out after $12 \mathrm{~h}$ and cooled naturally before loading.

\subsection{Loading and measurement}

The eccentric compression tests were conducted on a $500 \mathrm{t}$ universal hydraulic testing machine. The loading rate was controlled within $100 \mathrm{kN} /$ level. Before testing, each sample was preloaded at $10 \%$ of the test load such that it was in close contact with the machine, and the measuring instruments were verified to be normal. The macroscale phenomena of the sample in the loading process were observed and described. The sample strain was collected by the DH5922N dynamic signal test and analysis system (Donghua Testing Technology Co., Ltd., China). The displacement of the sample was captured by dial gauges. These data were used to analyze the effects of high temperature on the IPC columns. 


\section{TEST AND RESULTS ANALYSIS}

\subsection{Columns with large eccentricity}

\subsubsection{Macroscale phenomena}

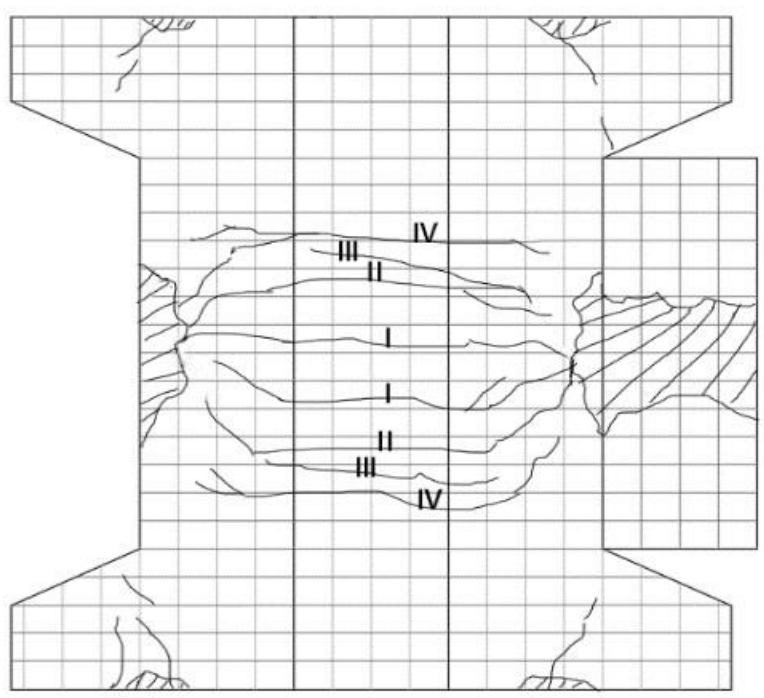

Figure 3. Crack evolution of columns with large eccentricity under compression

The compressive damages of IPC columns with large eccentricity were described as follows: With the growth in eccentric compression, the IPC on the tension side started to crack from middle to the two sides; the surface cracks on the back of the column gradually deepened and met the cracks on the two sides of the column, eventually forming curved transverse cracks across the entire column. When the load reached a certain level, the compressive concrete on the inside of the column peeled off first. When the load further increased to near the ultimate load, the compressive concrete was crushed, the bars on the tension side yielded, and the sample suffered from compressive failure. In this case, the concrete at the joint between the corbels and the column body exhibited slight cracking and spalling, plus a few oblique upward cracks.
Figure 3 presents the crack propagation of IPC columns failing under large eccentric load.

\subsubsection{Compressive strength}

There is no universal method to compute the post-fire compressive strength of IPC columns under eccentric load. Here, the compressive strength of ordinary concrete under large eccentric load was computed as per the Code for Design of Concrete Structures [16], and that of the IPC was calculated according to U. Schneider's trilinear compressive strength formula for the IPC $[17,18]$ :

$$
\begin{gathered}
f_{i c}(T)=f_{i c} \quad(20 \leq T \leq 200) \\
f_{i c}(T)=[1+0.000513(T-200)] f_{i c} \quad(200 \leq T \leq 400) \\
f_{i c}(T)=[1.025-0.00253(T-400)] f_{i c}(400 \leq T \leq 600)
\end{gathered}
$$

where, $f_{i c}(T)$ and $f_{i c}$ are the standard compressive strengths of the IPC under high temperature and normal temperature, respectively.

The computed compressive strengths of the IPC under high temperature are recorded in Table 3 . The error was computed as $\left(1-f_{c u} / f_{c u}{ }^{T}\right) \%$, where $f_{c u}{ }^{T}$ and $f_{c u}$ are the test value and computed value of compressive strength.

As shown in Table 3, the compressive strength of all IPC samples increased slightly at $400{ }^{\circ} \mathrm{C}$ from the level at normal temperature, and reduced at $600{ }^{\circ} \mathrm{C}$ to about half of that at normal temperature.

The next step is to analyze the effects of high temperature field on the compressive strength of the IPC columns. The temperatures on the surface, at the depth of $60 \mathrm{~mm}$ and at the center of each sample were measured by the embedded thermocouples. The temperatures in other parts were obtained by linear interpolation. The temperatures of the samples were displayed in Table 4.

The cracking load and ultimate load of each sample under each test condition were measured and recorded in Table 5. The loss ratio, i.e. the loss of compressive strength, of each IPC column under each test condition, was defined as $\left(\mathrm{N}_{\mathrm{u}}^{\mathrm{T}} / \mathrm{N}_{\mathrm{u}}{ }^{\mathrm{N}}\right) \%$, where $\mathrm{N}_{\mathrm{u}}^{\mathrm{T}}$ is the measured value at $400{ }^{\circ} \mathrm{C}$ or $600{ }^{\circ} \mathrm{C}$ and $\mathrm{N}_{\mathrm{u}}^{\mathrm{N}}$ is the measured value at normal temperature.

Table 3. Standard compressive strengths of the IPC samples (unit: MPa)

\begin{tabular}{ccccc}
\hline Fire temperature & Fire time & Test value & Computed value & Error \\
\hline Normal temperature & - & 46.7 & 46.7 & - \\
$400^{\circ} \mathrm{C}$ & Constant temperature for $1 \mathrm{~h}$ & 49.1 & 51.5 & $4.9 \%$ \\
$600^{\circ} \mathrm{C}$ & Constant temperature for 1h & 24.9 & 24.2 & $2.9 \%$ \\
$600^{\circ} \mathrm{C}$ & Constant temperature for 2h & 20.1 & - & - \\
\hline
\end{tabular}

Table 4. Temperatures of each isotherm in each IPC column

\begin{tabular}{ccccc}
\hline Part & DP1 & DP2 & DP3 & DP4 \\
\hline Center & Normal temperature & 68.5 & 100.8 & 132.6 \\
60mm deep & Normal temperature & 234.3 & 350.4 & 366.3 \\
Surface & Normal temperature & 400 & 600 & 600 \\
\hline
\end{tabular}

As shown in Table 5, the ultimate load of the IPC at $400{ }^{\circ} \mathrm{C}$ was $12.9 \%$ lower than that at normal temperature, the ultimate load of the IPC at $600{ }^{\circ} \mathrm{C}$ for $1 \mathrm{~h}$ was $18.1 \%$ lower than that at normal temperature, and the ultimate load of the IPC at $600{ }^{\circ} \mathrm{C}$ for $2 \mathrm{~h}$ was $22.2 \%$ lower than that at normal temperature. The decrements are almost linearly distributed, revealing that the ultimate compressive strength of the IPC decreased with the growth in fire temperature and fire time. According to Li et al. research [19], the compressive strength of ordinary concrete columns under large eccentric load decreased by $15.2 \%$ at $400{ }^{\circ} \mathrm{C}$ from the level at normal temperature, and by $35.6 \%$ at $600{ }^{\circ} \mathrm{C}$ from the level at normal temperature. Comparing our test data with Fan's results, the IPC columns had a far smaller loss of ultimate compressive strength than ordinary concrete columns under high fire temperature, an evidence of the excellent fire resistance of the IPC

Table 5. Test results on IPC columns with large eccentricity

\begin{tabular}{ccccc}
\hline Sample number & DP1 & DP2 & DP3 & DP4 \\
\hline Ultimate load/kN & 990 & 862 & 811 & 770 \\
Crack load/kN & 500 & 440 & 400 & 370 \\
Loss ratio/\% & - & 12.9 & 18.1 & 22.2 \\
\hline
\end{tabular}


In addition, the crack load of each sample was about 50\% of its ultimate load, indicating that the transverse cracks appeared late and extended rapidly on the IPC columns. With the gradual increase in the fire temperature, the crack load and ultimate load of each sample both declined continuously, but the ratio between the two loads remained the same. Under the same fire temperature, the longer the fire time, the more serious the damages inside the concrete, and the lower the compressive strength under large eccentric load; Under the same fire time, the higher the fire temperature, the greater the loss ratio; When the fire temperature increased within a certain range, the strength of the IPC could increase from the level at normal temperature, but its ultimate compressive strength continued to decline.

\subsubsection{Longitudinal displacement}

Figure 4 shows the load-longitudinal displacement curves of columns with large eccentricity. Under different temperatures, each of the four curves has a rising segment and a falling segment. In the early phase of loading, the displacement of each sample increased linearly with the growing load, and the curve was increasingly steep, as the IPC became denser and carried the load with the bars. When the load reached the ultimate strength, many penetrating curved transverse cracks appeared on the IPC surface at the distant tension side. In this case, the IPC no longer functioned properly and the bars also yielded. Meanwhile, the compressive concrete was crushed and severely cracked vertically until complete failure. The compressive test results show that, under high-temperature large eccentric compression, the IPC columns had a similar failure process as ordinary concrete columns, with a lower ultimate load than the latter.

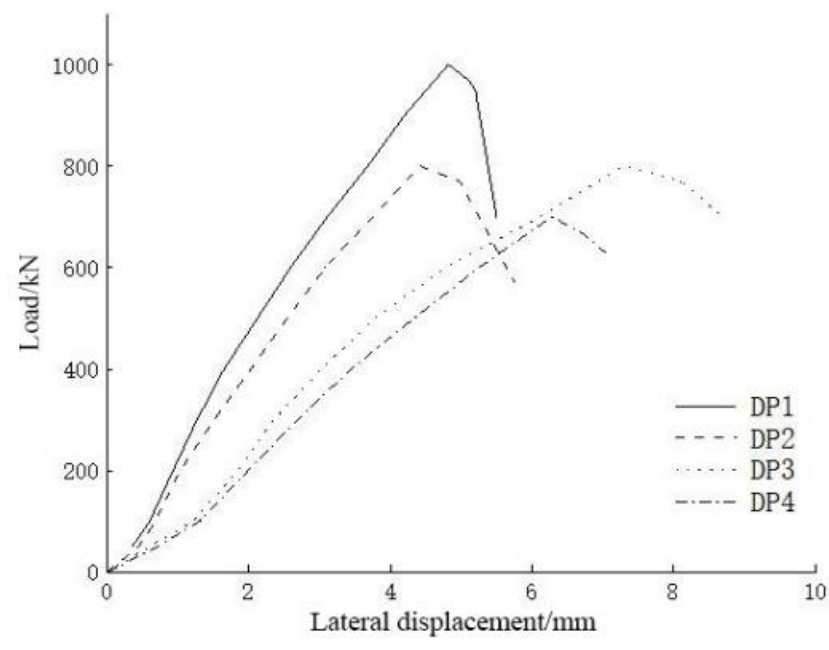

Figure 4. The load-longitudinal displacement curves of columns with large eccentricity

The following can be found by comparing the four curves in Figure 4:

(1) Without changing the other conditions, among the samples with the same fire time, the sample under high fire temperature had a low peak load (DP3 $<$ DP $2<\mathrm{DP} 1)$; among the samples under the same fire temperature, the sample with a long fire time had a low peak load (DP4 $<$ DP3).

(2) Without changing the other conditions, the sample at a high fire temperature had a smooth falling segment in its loadlongitudinal displacement curve.

\subsubsection{Lateral displacement}

The lateral displacement of each column was measured by dial gauges at the midpoint and the highest and lowest quarter points on the back side. The measured results show that the lateral displacement increased with the eccentric load; the load-lateral displacement curve of each sample was basically symmetric about the midpoint (i.e. the displacement declined in the same trend from the peak value at the midpoint to the taller or lower points), similar to the half cycle of sine wave. The lateral displacement of each sample changed insignificantly as the fire temperature increased from the normal level to $400^{\circ} \mathrm{C}$, but surged up as the temperature climbed to $600^{\circ} \mathrm{C}$. Under $600^{\circ} \mathrm{C}$, the lateral displacement increased with the fire time. This may be attributable to the thorough extension of cracks, as the sample become less elastic and rigid with the elapse of fire time.

The midpoint displacement curves of the samples are presented in Figure 5. Each curve consists of three parts: a linear rising segment, a nonlinear rising segment and a falling segment. Similarly, the midpoint transverse displacement first increased linearly with the rising load. However, when the load approached the ultimate strength, the growth of midpoint transverse displacement slowed down, but the lateral displacement still grew rapidly. In Figure 5, the curve slopes gradually declined after the bars had yielded, and tended to be stable after the peak load.

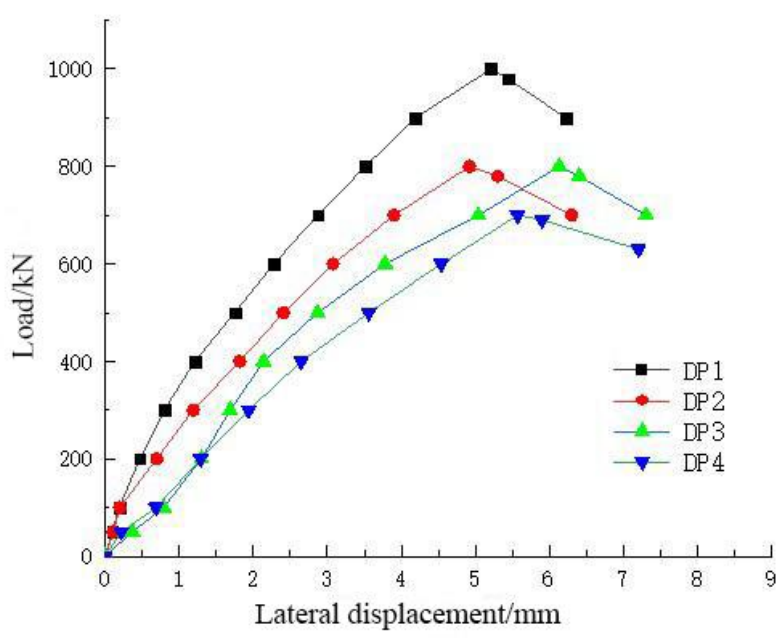

Figure 5. Load-midpoint lateral displacement curves of columns with large eccentricity

As shown in Figure 5, the lateral displacement is greatly affected by fire temperature. The compressive strength of each sample gradually decreased with the rise in temperature. Compared with those at high temperature, the samples at a low fire temperature had steep falling segments in their load-lateral displacement curves, a signal of poor ductility and high peak load.

\subsection{Columns with small eccentricity}

\subsubsection{Macroscale phenomena}

The compressive damages of IPC columns with small eccentricity were described as follows: With the growth in eccentric compression, some vertical cracks appeared in the compressive IPC and continued to propagation to the two sides, while several curved transverse cracks across the entire column emerged on the tension side. When the load further to 
the ultimate load, the compressive concrete was crushed suddenly and fell off from the column, the concrete on the tension side cracked transversely under the tensile force, and the corbels only witnessed slight cracks and IPC spalling in local areas. During the failure of IPC columns with small eccentricity, the compressive IPC fell off in large blocks, the samples lost the compressive strength, and the damaged section was rather long, showing the features of brittle failure. The crack propagation of these columns is illustrated in Figure 6.

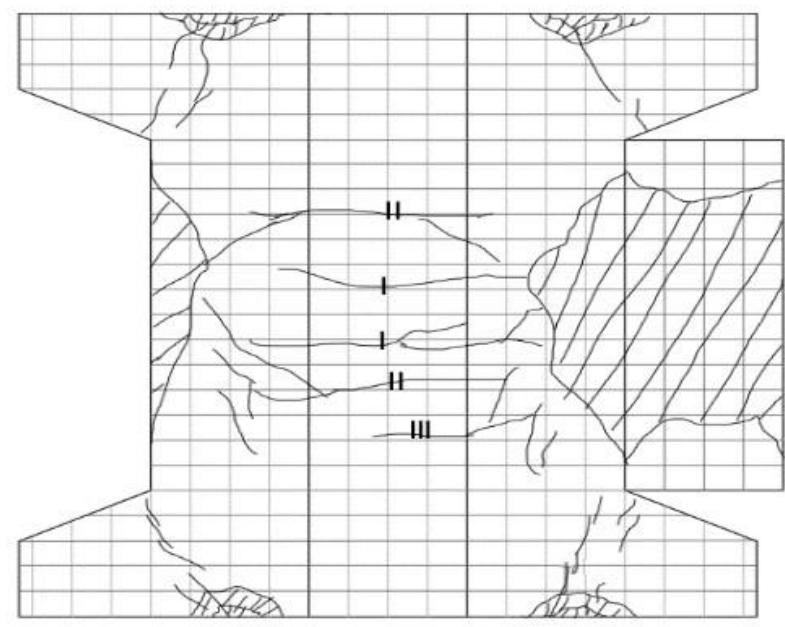

Figure 6. Crack evolution of columns with small eccentricity under compression

\subsubsection{Compressive strength}

The compressive strength of columns with small eccentricity was analyzed similarly as that of columns with large eccentricity. The temperature field distribution inside the concrete was measured by thermocouples, and the decline of compressive strength was described by the loss ratio. The concrete ductility was discussed based on the crack load and ultimate load. The test results on columns with small eccentricity are listed in Table 6.

Table 6. The test results on columns with small eccentricity

\begin{tabular}{ccccc}
\hline Sample number & XP5 & XP6 & XP7 & XP8 \\
\hline Ultimate load/kN & 2,087 & 1,624 & 1,488 & 1,380 \\
Crack load/kN & 850 & 760 & 750 & 700 \\
Loss ratio/\% & - & 22.2 & 28.7 & 33.9 \\
\hline
\end{tabular}

As shown in Table 5, the ultimate load of the IPC at $400{ }^{\circ} \mathrm{C}$ was $22.9 \%$ lower than that at normal temperature, the ultimate load of the IPC at $600{ }^{\circ} \mathrm{C}$ for $1 \mathrm{~h}$ was $28.7 \%$ lower than that at normal temperature, and the ultimate load of the IPC at $600{ }^{\circ} \mathrm{C}$ for $2 \mathrm{~h}$ was $33.9 \%$ lower than that at normal temperature. The decrements basically obey the linear distribution. Compared with the ultimate compressive strength of IPC with large eccentricity, the IPC with small eccentricity had a large loss ratio yet a large load.

Furthermore, the large ratio between crack load to ultimate load indicates that transverse cracks appeared late and extended rapidly on the IPC columns. With the rising fire temperature, the crack load and ultimate load of each sample both declined continuously, but the ratio between the two loads gradually increased. Under the same fire time, the higher the fire temperature, the weaker the IPC strength and the lower the compressive strength of the column; Under the same fire temperature, the longer the fire time, the more serious the damages of the IPC, and the lower the compressive strength; When the fire temperature increased within a certain range, the strength of the IPC could increase, but its ultimate compressive strength continued to decline.

The following can be obtained by comparing the test results on IPC columns with large and small eccentricities

(1) Under any fire temperature, the IPC columns with large and small eccentricities have greater ultimate strength than common concrete columns, revealing the better hightemperature resistance of the IPC.

(2) Under the same fire time, the compressive strength of a IPC column, whether with large or small eccentricity, always decreases with the rising fire temperature; The IPC column with small eccentricity suffers from a larger loss ratio of compressive strength than that with large eccentricity.

\subsubsection{Longitudinal displacement}

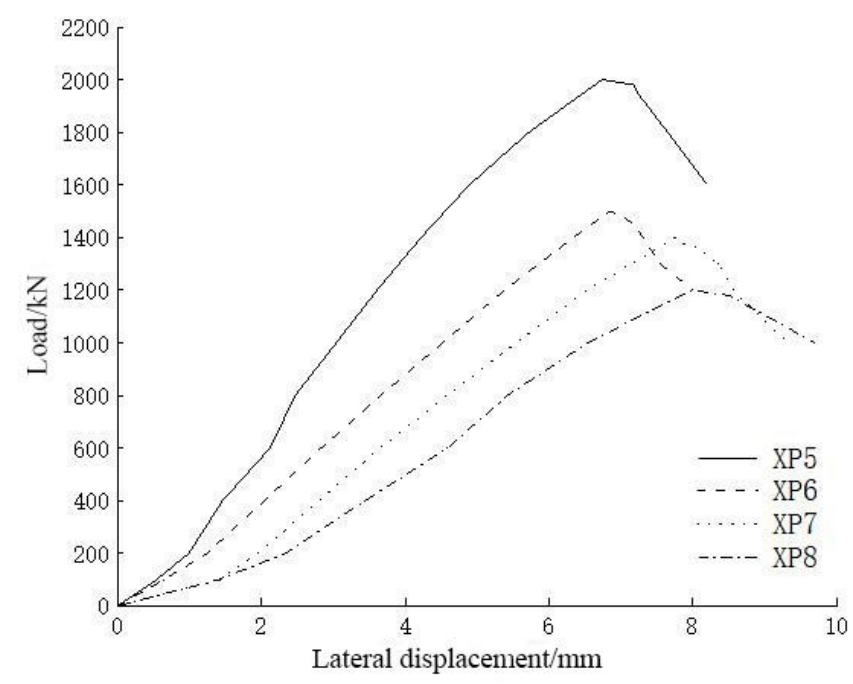

Figure 7. The load-longitudinal displacement curves of columns with small eccentricity

Figure 7 shows the load-longitudinal displacement curves of columns with small eccentricity. Under all four temperatures, each of the four curves contains a rising segment and a falling segment. In the early phase of loading, the displacement of each sample increased linearly with the rising load, and the curve was increasingly steep, as the IPC became denser and carried the load with the bars. When the load reached the ultimate strength, many penetrating curved transverse cracks appeared on the IPC at the tension side, while the compressive concrete was crushed. After the peak load, the displacement increased rapidly, while the load plunged deeply.

The following can be found by comparing the four curves in Figure 7:

(1) Under the same fire time, the sample under high fire temperature had a low peak load (XP7 $<$ XP6 $<$ XP5); Under the same fire temperature, the sample with a long fire time had a low peak load $(\mathrm{XP} 8<\mathrm{XP7})$.

(2) Without changing the other conditions, the sample at a high fire temperature had a smooth falling segment in its loadlongitudinal displacement curve.

(3) Under the same fire temperature, the IPC columns with small eccentricity had lower peak loads than those with large eccentricity. 


\subsubsection{Lateral displacement}

The lateral displacement of IPC columns with small eccentricity was discussed similarly as those with large eccentricity. The lateral displacement of each column with small eccentricity was measured by three dial gauges, arranged at the same positions as those for the columns with large eccentricity. Obviously, the columns at $600{ }^{\circ} \mathrm{C}$ had a greater lateral displacement than those at normal temperature and $400{ }^{\circ} \mathrm{C}$, which increased with the fire time. This means the ductility and elasticity of the column decreased to different degrees when the temperature was high, or when the fire time increased at a constant temperature. The midpoint displacement curves of the samples are presented in Figure 8.

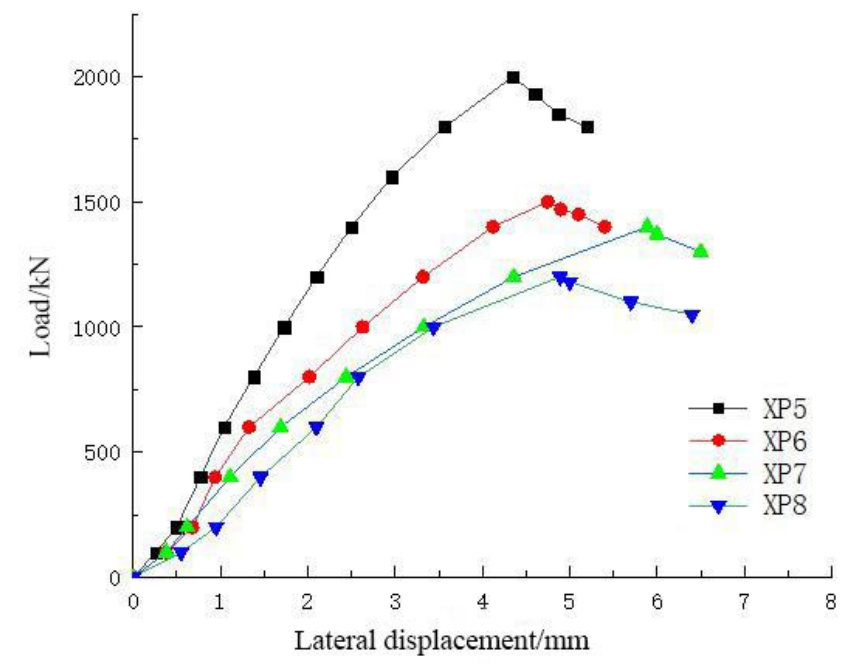

Figure 8. Load-midpoint lateral displacement curves of columns with small eccentricity

In the early phase of loading, the midpoint lateral displacement of each sample basically increased linearly with the growing load. After reaching the peak load, the load increased at a slower rate, the sample's lateral displacement rocketed up, and the curve became stable. Comparing the four curves, it can be learned that the lateral displacement was greatly affected by temperature; with the increase in fire temperature, the load-midpoint lateral displacement curve of each sample became less steep, and the peak load exhibited a declining trend. Under the same temperature, the IPC columns with small eccentricity had lower peak loads than those with large eccentricity.

\section{CONCLUSIONS}

(1) Under high-temperature loading, the IPC samples cracked by different degrees, and saw obvious changes in color. With the increase in fire temperature and fire time, the cracks on each sample got denser and wider; On the columns, water stains emerged in certain areas, holes appeared in varied degrees, and some edges and corners were loose and falling.

(2) The strength of the IPC could grow when the fire temperature increased within a certain range. On the level of structural member, however, the growth in fire temperature and fire time will reduce the compressive strength of the IPC member, push up the displacement under peak load, and reduce the ultimate load.

(3) The PIC enjoys better high-temperature resistance and smaller loss ratio under eccentric compression than ordinary concrete. Therefore, the PIC is more favorable for building fire prevention than ordinary concrete.

\section{ACKNOWLEDGMENT}

Foundation and frontier project of Chongqing Science and Technology Commission (No. cstc2016jcyjA5659).

\section{REFERENCES}

[1] Li, M., Qian, C.X., Sun, W. (2004). Mechanical properties of high-strength concrete after fire. Cement \& Concrete Research, 34(6): 1001-1005. https://doi.org/10.1016/j.cemconres.2003.11.007

[2] Stawiski, B. (2006). Attempt to estimate fire damage to concrete building structure. Archives of Civil \& Mechanical Engineering, 6(4): 23-29. https://doi.org/10.1016/S1644-9665(12)60273-8

[3] Yu, D. (2017). Experimental study on anti-seismic property of inorganic polymer concrete short columns after high temperature, Annales de Chimie - Science des Matériaux, 41(3-4): 225-237. https://doi.org/10.3166/ACSM.41.225-237

[4] Fan, X.C., Chen, Y.W., Chen, H. (2014). Experimental research on basic mechanical properties of inorganic polymer concrete. Applied Mechanics \& Materials, 584586:

955-959. https://doi.org/10.4028/www.scientific.net/AMM.584586.955

[5] Luo, X., Xu, J.Y., Bai, E.L., Li, W. (2013). Research on the dynamic compressive test of highly fluidized geopolymer concrete. Construction \& Building Materials, 48(19): 166-172. https://doi.org/10.1016/j.conbuildmat.2013.06.035

[6] Jin, X., Lu, Z., Fan, X. (2013). Experimental study on stress-strain curves of inorganic polymer concrete. Concrete, 45(11): 58-60.

[7] Lu, Z., Jin, X., Fan, X. (2012). Experimental study and finite element analysis of reinforced inorganic polymer concrete beam. Applied Mechanics \& Materials, 193-194 891-896.

https://doi.org/10.4028/www.scientific.net/AMM.193194.891

[8] Sofi, M., Deventer, J.S.J.V., Mendis, P.A., Lukey, G.C. (2007). Engineering properties of inorganic polymer concretes (IPCs). Cement \& Concrete Research, 37(2): 251-257. https://doi.org/10.1016/j.cemconres.2006.10.008

[9] You, C.Z., Fan, X.C., Wu, D., Pu, L.P. (2016). Experimental research on temperature-stress of inorganic polymer concrete. Applied Mechanics \& Materials, 405408(1): 2795-2800 https://doi.org/10.4028/www.scientific.net/AMM.405408.2795

[10] Kim, Y.J., Siriwardanage, T., Hmidan, A., Seo, J. (2014). Material characteristics and residual bond properties of organic and inorganic resins for CFRP composites in thermal exposure. Construction \& Building Materials, 50(2): 631-641. https://doi.org/10.1016/j.conbuildmat.2013.10.009

[11] Chen, Z., Ye, P., Xue, J., Zhou, C. (2014). Mechanical 
properties of steel reinforced recycled aggregate concrete eccentric compression column after high temperature. Industrial Construction. https://doi.org/10.13204/j.gyjz201411007

[12] Liu, H., Lu, Z., Peng, Z. (2015). Test research on prestressed beam of inorganic polymer concrete. Materials \& Structures, 48(6): 1919-1930. https://doi.org/10.1617/s11527-014-0283-x

[13] Liu, H.H., Lu, Z. (2013). Test research and analysis of reinforced inorganic polymer concrete beam under bending. Applied Mechanics \& Materials, 256-259: 702705.

https://doi.org/10.4028/www.scientific.net/AMM.256259.702

[14] Pan, Z., Sanjayan, J.G., Kong, D.L.Y. (2012). Effect of aggregate size on spalling of geopolymer and Portland cement concretes subjected to elevated temperatures. Construction \& Building Materials, 36: 365-372. https://doi.org/10.1016/j.conbuildmat.2012.04.120

[15] Pan, Z., Sanjayan, J.G., Collins, F. (2014). Effect of transient creep on compressive strength of geopolymer concrete for elevated temperature exposure. Cement and Concrete Research, 56: 182-189. https://doi.org/10.1016/j.cemconres.2013.11.014

[16] Zhang, J., Liu, Z., Hua, Y. (2007). Research on temperature effect combination in the design of concrete structure. Industrial Construction, 37(1): 42-46. https://doi.org/10.13204/j.gyjz2007.01.012

[17] Schneider, U. (1988). Concrete at high temperatures-A general review. Fire Safety Journal, 13(1): 55-68. https://doi.org/10.1016/0379-7112(88)90033-1

[18] Zhou, T., Jia, Y., Xu, M., Wang, X., Chen, Z. (2015). Experimental study on the seismic performance of Lshaped column composed of concrete-filled steel tubes frame structures. Journal of Constructional Steel Research, 114: 77-88. https://doi.org/10.1016/j.jcsr.2015.07.009

[19] Li, Z., Xu, J., Bai, E. (2012). Static and dynamic mechanical properties of concrete after high temperature exposure. Materials Science \& Engineering A, 544: 2732. https://doi.org/10.1016/j.msea.2012.02.058 